\title{
ERRATUM INFRARED ABSORPTION SPECTRUM OF SINGLY IONIZED MAGNETISM DONORS IN SILICON
}

\author{
L. T. Ho, F. Y. Lin, and W. J. Lin \\ Institute of Physics \\ Academia Sinica \\ Taipei, Taiwan 115 \\ Republic of China
}

Received February 23, 1993

The original paper appeared in International Journal of Infrared and Millimeter Waves, Volume 14, Number 5 (May 1993), pages 1099-1106. Due to an error, the last line of the authors' affiliation printed incorrectly. The correct affiliation is as printed above.

The publisher regrets any inconvenience this may have caused. 